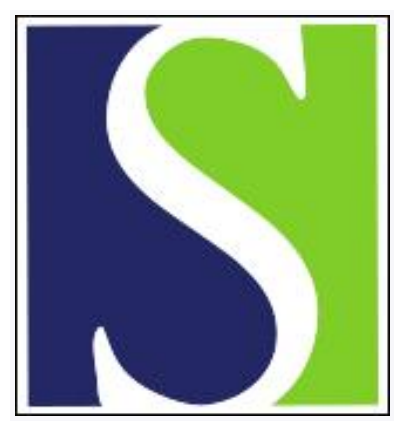

Scand J Work Environ Health 1981;7(1):1-7

https://doi.org/10.5271/sjweh.2570

Issue date: Mar 1981

Human response to controlled levels of combinations of sulfur dioxide and inert dust.

by Andersen I, Mølhave L, Proctor DF

Key terms: airway resistance; combination; controlled level; discomfort; environmental chamber; human response; inert dust; mucociliary clearance; nose; particle; rhinomanometry; sulfur dioxide; vanadium; workroom air

This article in PubMed: www.ncbi.nlm.nih.gov/pubmed/7313606

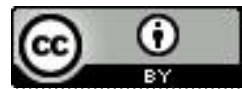




\title{
Human response to controlled levels of combinations of sulfur dioxide and inert dust
}

\author{
by Ib Andersen, MD,' Lars Mølhave, MSc, ${ }^{1}$ Donald F Proctor, MD ${ }^{2}$
}

\begin{abstract}
ANDERSEN I, MØLHAVE L, PROCTOR DF. Human response to controlled levels of combinations of sulfur dioxide and inert dust. Scand $j$ work environ health 7 (1981) 1-7. Under controlled conditions in an environmental chamber 16 healthy young volunteers were exposed to combinations of sulfur dioxide $\left(\mathrm{SO}_{2}\right)\left(2.6\right.$ or $\left.13 \mathrm{mg} / \mathrm{m}^{3}\right)$ and inert plastic dust $\left(2\right.$ or $\left.10 \mathrm{mg} / \mathrm{m}^{3}\right)$ or of $\mathrm{SO}_{,}\left(13 \mathrm{mg} / \mathrm{m}^{3}\right)$ and dust $\left(10 \mathrm{mg} / \mathrm{m}^{3}\right)$ coated with vanadium. During periods in clean air and during exposures of 5 - $h$ duration nasal mucus flow rate, nasal airflow resistance, forced vital capacity, and subjective discomfort were measured. Reductions in nasal mucus flow rate, forced expiratory flow $\left(\mathrm{FEF}_{25-75} \%\right.$ ), and discomfort were related principally to the $\mathrm{SO}_{2}$ concentration. The combined effects of $\mathrm{SO}_{2}$ and dust were, at the most, additive, and there was no indication of potentiation effects. No effect could be attributed to the coating of the dust with vanadium.
\end{abstract}

Key terms: airway resistance, discomfort, environmental chamber, mucociliary clearance, nose, particles, rhinomanometry, vanadium, workroom air.

The effect of combinations of gases and particles on man is a topic of great theoretical and practical interest. Knowledge about the effects of pollutants is mainly based on exposure studies with a single pollutant without any admixtures. This situation is however very far from the real-life situation in outdoor air or indoors in the work environment, where many pollutants are present simultaneously. Therefore, investigations of the interacting effects of pollutants are important.

Two important pollutants of the outdoor air and the work environment are sulfur dioxide $\left(\mathrm{SO}_{2}\right)$ and dust. Earlier

1 Institute of Hygiene, University of Aarhus, Denmark.

2 Department of Environmental Health Sciences, Johns Hopkins School of Hygiene and Public Health, Baltimore, Maryland, United States.

Reprint requests to: Dr Ib Andersen, Arbejdsmiljøinstituttet, Baunegaardsvej 73, DK-2900 Hellerup, Denmark. w.e have reported studies of the effects of $\mathrm{SO}_{2}$ (at 1, 5 and $25 \mathrm{ppm}$ ) and of inert dust (at 2, 10 and $25 \mathrm{mg} / \mathrm{m}^{3}$ ) on the human nasal airway, on forced vital capacity, and on subjective discomfort $(4,7)$. The purpose of the present study was to evaluate, with the same experimental technique, the effects of exposures to 1 or $5 \mathrm{ppm}$ of $\mathrm{SO}_{2}\left(2.6\right.$ and $13 \mathrm{mg} / \mathrm{m}^{3}$, respectively) combined with 2 or $10 \mathrm{mg} / \mathrm{m}^{3}$ of an inert plastic dust. These conditions were not meant to be representative of any particular environment, but were instead meant to produce a high absorption of $\mathrm{SO}_{2}$ and a high deposition of dust in the nose. The highest concentrations of $\mathrm{SO}_{2}$ and dust used were equal to the timeweighted averages (TWAs) widely accepted as safe for workers over a 40 -h week (2). In one extra series the dust was coated with vanadium, a catalyst, which like carbon might increase the conversion of $\mathrm{SO}_{2}$ to sulfate $(1,9)$. 


\section{Materials and methods}

The study took place in an environmental chamber (3) at the Institute of Hygiene, Aarhus, Denmark. The subjects were 16 healthy university students, 8 female and 8 male, with an average age of $22 \mathrm{a}$ and age range of 19 to 28 a. None of them smoked heavily. Ten were nonsmokers, and six had smoked from 2 to 20 cigarettes per day for 1 to 9 a. Previous studies have detected no nasal function difference attributable to smoking - not a surprising fact since smokers deliberately draw the smoke through the mouth into the lungs. All had apparently healthy upper airways and were habitually nasal breathers. Nobody had a history of chronic or recent acute respiratory disease. The subjects were studied in groups of four (two males and two females), each group undergoing the five different exposures on five consecutive days. The schedule for each group is shown in table 1. A fixed schedule was used in the hope of avoiding the confusing carry-over effects demonstrated earlier for $\mathrm{SO}_{2}$ (4).

Each day began in the chamber with a control period with clean air at $23^{\circ} \mathrm{C}$ and $50 \%$ relative humidity $(\mathrm{RH})$, and the measurements each day during that period, together with a set of measurements performed prior to the first day (day 0), were taken as control values. Air supplied to the chamber was filtered through absolute and charcoal filters, and, during the control periods, no significant number of particles could be demonstrated in the unoccupied chamber with either an optical particle detector or a condensation nuclei counter. Air temperature was maintained at $23 \pm 0.5^{\circ} \mathrm{C}$ and $\mathrm{RH}$ at $50 \pm 5 \%$. The temperature of the chamber walls and air was identical. Air velocity was $10 \pm 3 \mathrm{~cm} /$

Table 1. Exposure conditions.

\begin{tabular}{cccc}
\hline Day & $\begin{array}{c}\text { Dust } \\
\left(\mathrm{mg} / \mathrm{m}^{3}\right)\end{array}$ & $\begin{array}{c}\text { Sulfur } \\
\text { dioxide } \\
\left(\mathrm{mg} / \mathrm{m}^{3}\right)\end{array}$ & $\begin{array}{c}\text { Vanadium } \\
\text { coating of } \\
\text { the dust }\end{array}$ \\
\hline & & & \\
1 & 2 & 2.6 & none \\
2 & 2 & 13 & none \\
3 & 10 & 2.6 & none \\
4 & 10 & 13 & none \\
5 & 10 & 13 & + \\
\hline
\end{tabular}

$\mathrm{s}$, and air was supplied at a rate of $500 \mathrm{~m}^{3} / \mathrm{h}$ without recirculation. Two fans thoroughly mixed the air in the chamber. The chamber has been described more fully elsewhere (3). It had a floor area of $19 \mathrm{~m}^{2}$ and a volume of $49 \mathrm{~m}^{3}$. During the exposure period $99.975 \% \mathrm{SO}_{2}$ was metered through rotameters to the inlet duct. The concentration in the chamber was continuously monitored with a conductivity method.

The dust employed in the study was a finely divided, fully polymerized plastic impregnated with carbon black (Rank Xerox toner 6R90005). The dust was chosen because the particles had an AED (aerodynamic equivalent diameter) of 2.2 to $15.3 \mu \mathrm{m}, 55 \%$ of the particles by number and $27 \%$ by weight having an AED of 1.9 to $8.9 \mu \mathrm{m}$. A complete description of the dust, its generation as an aerosol, and its measurement has been given in a previous paper (7). Dust concentration and particle size were monitored every half hour by both gravimetric analysis and the optical microscopic counting of samples taken with a Konimeter ${ }^{\circledR}$ (C.Zeiss, VEB, Jena, German Democratic Republic). The dust used on day 5 was coated with vanadium, $0.58 \mathrm{mg} / \mathrm{g}$ of dust. The vanadium coating was performed by evaporation from a divanadium oxide solution in $50 \%$ ethyl alcohol, in which the particles were suspended. No significant changes in aerodynamic diameter resulted, and, by microscopy, vanadium crystals were never observed. The vanadium concentration was determined by atomic absorption spectrophotometry.

The first measurement each day was performed in clean air, whereas the second and the third measurements were made after $2-3$ and $4-5 \mathrm{~h}$ of exposure, respectively, to the pollutants. Each day the schedule of events was the same, the only variable was the level of exposure to $\mathrm{SO}_{2}$ and dust during the exposure periods. The concentrations were kept constant within $\pm 10 \%$ during the whole exposure period after an initial increase, which took about $45 \mathrm{~min}$.

During each series of measurements the procedure was as follows: We measured nasal mucociliary flow by external detection of the motion of a resin particle (diameter $0.056 \mathrm{~mm}$ ) labeled with $2 \mu \mathrm{Ci}$ of $\mathrm{Tc}^{99 \mathrm{~m}}$ placed under direct vision on the 
superior surface of the inferior turbinate, a point in the mainline of inspiratory airflow. The technique has been described fully in our previous papers $(4,7)$. On the completion of that test we measured nasal airfilow resistance through an oronasal plastic mask attached to a pneumotachometer. Air flow and oral pressure were displayed on a storage oscilloscope. From this curve we calculated an area proportional to the effective cross-sectional area of the nasal airway (4). Thereafter, we recorded the forced expiratory vital capacity (FVC) with a single breath instrument (Vitalograph ${ }^{\circledR}$, Vitalograph Ltd, Buckingham, England), from the record of which we later measured the forced expiratory volume in $1 \mathrm{~s}\left(\mathrm{FEV}_{1.0}\right)$ and calculated the forced expiratory flow $\left(\mathrm{FEF}_{25-75} \%\right)$. Finally we obtained samples of pharyngeal air for dust analysis by drawing chamber air through the nose and out the mouth at a flow rate of about $20 \mathrm{I} / \mathrm{min}$ while the subject performed a Valsalva maneuver. All of these procedures have been described fully in previous papers $(4,7)$.

Throughout each day the subjects were asked to adjust the pointer on a voting machine expressing degree of airway irritation on a scale of 0 (for complete comfort) to 100 (for severe discomfort). The position of each individual's pointer was concealed from fellow subjects, and it was recorded continuously. At the end of each day the subjects were also closely questioned as to the degree and nature of discomfort they had experienced. All procedures were in accord with the Helsinki declaration

Fluids were permitted ad libitum; lunch was served during the third hour; and subjects were allowed to walk about, play cards, or read as they wished. No smoking was allowed.

For the physiological measurements an analysis of variance was used (13). Due to a "within subject variation" and a variation between measurements performed on different days, the analysis was based on differences obtained by subtracting the values measured during the control condition from the values measured during the exposure period of the same day.

The results of the discomfort voting data were analyzed with the nonparametric Friedmann's test, as the assumptions for performing a parametric analysis of vari- ance were not fulfilled (11). The level of significance was always $5 \%$.

\section{Results}

\section{Nasal mucus flow}

Results on nasal mucus flow are available from 14 subjects only, as two subjects proved to have a mucostasis on the first day of exposure and during the rest of the study. To reduce the local radiation on the epithelium, we removed the tagged bead after $10 \mathrm{~min}$, and therefore no mucus flow measurements were obtained. In the prestudy investigation (day 0 ) these two subjects had normal mucus flow rates. There was no apparent reason for the mucostasis. The mucus membrane appeared normal, and there were no symptoms or signs indicating a common cold.

The average nasal mucus flow rates during the five different exposure conditions are shown for the 14 subjects in fig 1 . It appears that under the control conditions each day the flow rate was lower in the anterior and posterior thirds of the nose than in the mid portions. The results from day 1 (dust $2 \mathrm{mg} / \mathrm{m}^{3}, \mathrm{SO}_{2} 2.6 \mathrm{mg} / \mathrm{m}^{3}$ ) are shown in the left fifth of the figure, where the result of the preliminary investigation (day 0 , only one measurement) is also shown. The results of the measurements in clean air on day 0 and day 1 did not differ. During the pollutant exposures the mucus flow rate in the anterior third of the nose always decreased with time during exposure. In the middle third of the nose (slit 3 to 4) no effects of dust concentration or of the vanadium coating of the dust were found. Irrespective of the dust concentration, the flow rates were reduced in subjects exposed to $\mathrm{SO}_{2}$ ( $p<0.01$ for $\mathrm{SO}_{2} 2.6 \mathrm{mg} / \mathrm{m}^{3}$ and $\mathrm{p}<0.001$ for $\mathrm{SO}_{2} 13 \mathrm{mg} / \mathrm{m}^{3}$ ). The effect of the $\mathrm{SO}_{2}$ concentration of $13 \mathrm{mg} / \mathrm{m}^{3}$ was greater than that of $2.6 \mathrm{mg} / \mathrm{m}^{3}(\mathrm{p} \simeq 0.03)$. In the posterior third of the nose no exposure effects appeared. The responses of the male and female subjects and of the smokers and nonsmokers did not differ.

\section{Airway resistance}

The results for airway resistance were based on measurements from 16 subjects. 

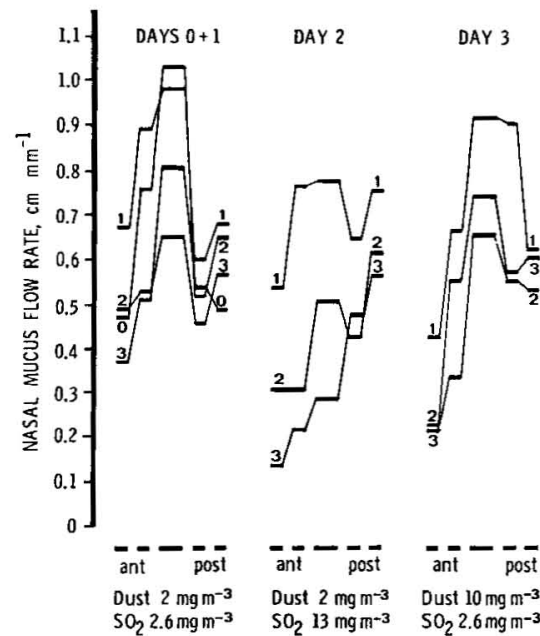

Dust $2 \mathrm{mg} \mathrm{m}^{-3}$ $\mathrm{SO}_{2} 13 \mathrm{mg} \mathrm{m}^{-3}$
Dust $10 \mathrm{mg} \mathrm{m}^{-3}$ $\mathrm{SO}_{2} 2.6 \mathrm{mg} \mathrm{m}^{-3}$

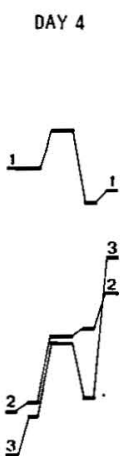

$\overline{\text { ant }}-\overline{\text { post }}$

Dust $10 \mathrm{mg} \mathrm{m}^{-3}$ $\mathrm{SO}_{2} 13 \mathrm{mg} \mathrm{m}^{-3}$
DAY $S$

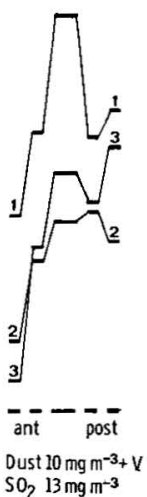

Fig 1. Average mucus flow rates at five different positions in the nose. The two positions marked ant and post represent the anterior and posterior thirds of the ciliated part of the epithelium, respectively. The first measurement each day (number 1 on the curves) and the preliminary investigation on day 0 were performed in clean air, whereas the second and third measurements (numbers 2 \& 3 on the curves) were performed after 2 or $4 \mathrm{~h}$ of continuous exposure to the pollutants. The average standard deviation of the mean was $14 \%$.
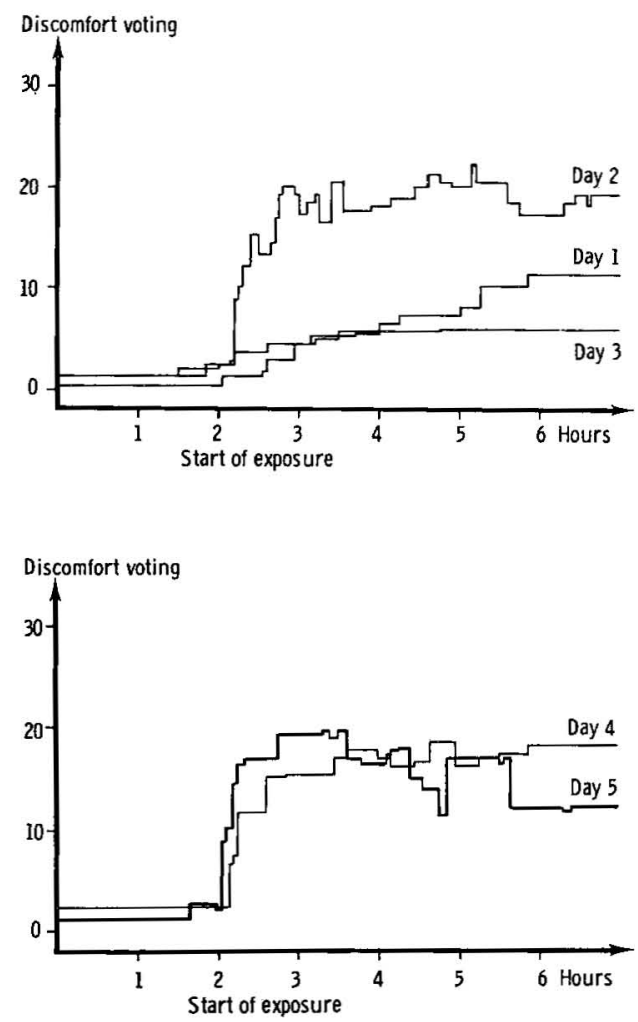

Fig 2. Variation of the mean discomfort vote with time. The scale was from 0 to 100 representing no discomfort and intolerable discomfort, respectively.

The airflow resistance has been expressed as the cross-sectional nasal area. Irrespective of the dust concentration, exposure to $\mathrm{SO}_{2}$ altered the cross-sectional nasal area. The $\mathrm{SO}_{2}$ concentration of $2.6 \mathrm{mg} / \mathrm{m}^{3}$ caused a decrease $(p<0.01)$ and that of $13 \mathrm{mg} / \mathrm{m}^{3}$ caused an increase. No other effects were found.

The forced expiratory test showed no significant changes in $\mathrm{VC}$ and $\mathrm{FEV}_{1.0}$ at any exposure. The $\mathrm{FEF}_{25-75} \%$ was significantly reduced during exposure to high $\mathrm{SO}_{2}$ concentrations on days 2 and 4 . There was no difference in the response of smokers and nonsmokers.

The measurements of dust particles in the air after nasal transit in relation to the same measurement in chamber air revealed an effectiveness of the nasal filter similar to that reported in our study of inert dust alone (7). $\mathrm{SO}_{2}$ was not measured in pharyngeal air during this study. The nasal absorption of $\mathrm{SO}_{2}$ has been described in a previous paper (4).

The average subjective discomfort votes, as indicated on the voting apparatus, are shown in fig 2 . In the control periods the voting never exceeded two units on a scale from 0 to 100 . When the pollutants were added to the air, the discomfort increased in almost direct proportion to the concentration of the pollutants. The responses on day 1 and 3 were very similar, as was also true for days 2,4 , and 5 .

The discomfort votings during exposure to any combination of $\mathrm{SO}_{2}$ and dust were all significantly increased when compared to votings during clean air exposures $(p<0.01)$. There was no difference be- 
tween the votings during exposure to the two different dust concentrations and with or without a vanadium coating. The discomfort was greater during high than during low levels of exposure to $\mathrm{SO}_{2}$. The average voting never exceeded 20 on a scale of 0 to 100 , where the scale from 0 to 33 was marked "slight discomfort."

We also asked about the symptoms experienced in the chamber at the end of each day, and we repeated the questions the following morning. The questions covered eye, nose, mouth, throat and lower airway, irritation, sneezing and coughing, headache, and dizziness. After these specific questions the subjects were asked if they had experienced symptoms other than those mentioned. The main complaint was irritation of the nose and throat, most often expressed as a feeling of dryness. The number of subjects with these complaints on days 1 through 5 was $5,11,5$, 8 , and 9 , respectively. It appears that this irritation effect was the most pronounced the days on which the highest $\mathrm{SO}_{2}$ concentration was used. The following morning all the symptoms had disappeared.

\section{Discussion}

In the literature there are very few studies of the combined effect of TWA levels of $\mathrm{SO}_{2}$ and aerosols on human subjects. Frank et al (10), Snell \& Luchsinger (12), and Burton et al (8) studied the effects of sodium chloride aerosol and $\mathrm{SO}_{2}$ on airway resistance during $15-30 \mathrm{~min}$ of exposure, but none of them were able to demonstrate in man the potentiation found due to this combination in experiments with guinea pigs (1). Ulmer (14) studied 16 subjects exposed $8 \mathrm{~h} / \mathrm{d}$ for $4 \mathrm{~d}$ to a combination of $\mathrm{SO}_{2}\left(17 \mathrm{mg} / \mathrm{m}^{3}\right)$ and coal dust $\left(8 \mathrm{mg} / \mathrm{m}^{3}\right)$. The addition of coal dust did not influence the increase of airway resistance caused by $\mathrm{SO}_{2}$. No previous study exists of the effects of combinations of $\mathrm{SO}_{2}$ and dust on human nasal airways.

Our present study was carried out with exactly the same techniques as in two previous studies, one on the effects of $\mathrm{SO}_{2}$ (4) and the other on inert plastic dust (7). In fig 3 and 4 the results of the present study and the two previous ones are compared. The measurements of the three groups had different means even under
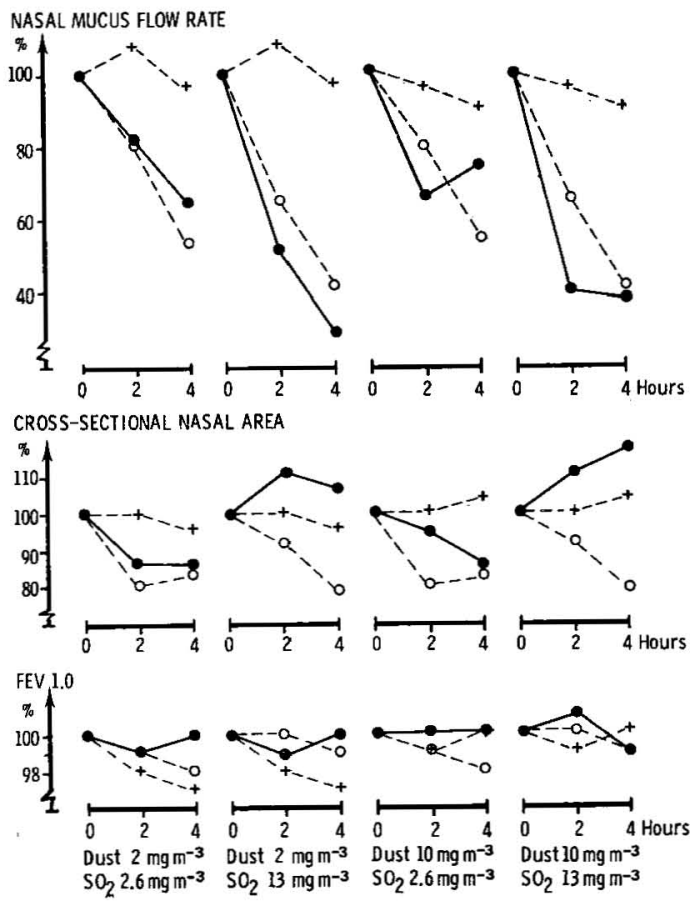

Fig 3. Variation of the average nasal mucus flow rate with time at slit 3-4 (upper part) and of the average cross-sectional nasal area and $\mathrm{FEV}_{1.0}$ (middle and lower parts, respectively). The standard deviations of the mean were 11, 11 , and $5 \%$, respectively. For each condition the results are expressed as the percentage of the control value in clean air on the same day. [ = combined exposures to sulfur dioxide $\left(\mathrm{SO}_{2}\right)$ and dust, $\mathrm{O}=$ exposure to $\mathrm{SO}_{2}$ only, $+=$ exposure to dust only; the data for the two lastmentioned exposures are from Andersen et al $(4,7)]$

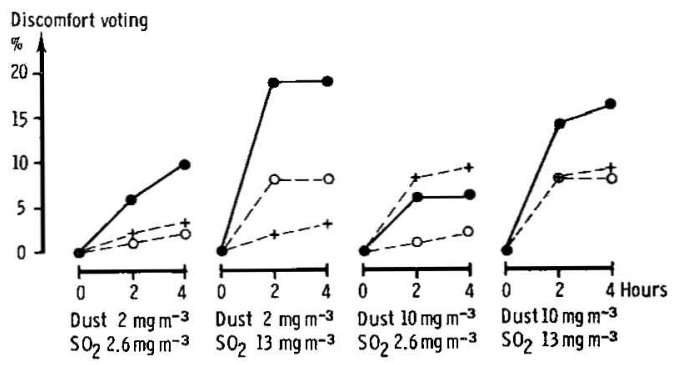

Fig 4. Variation of the average discomfort voting with time. [ $[=$ combined exposure to sulfur dioxide $\left(\mathrm{SO}_{2}\right)$ and dust, $\mathrm{O}=$ exposure to $\mathrm{SO}_{2}$ only, $+=$ exposure to dust only; the data for the two last-mentioned exposures are from Andersen et al $(4,7)]$ 
the control conditions, and therefore the measurements for each group, under any condition, have been expressed as the percentage of the measurements made under the control conditions in clean air on the same day. To enable a comparison between the three experiments, an analysis of variance similar to that used in the present study was performed on the results from the previous two exposure experiments. The calculations were based on the data obtained at concentrations similar to those in the combination study, and therefore the results from the highest $\mathrm{SO}_{2}$ and dust levels (65 and $25 \mathrm{mg} / \mathrm{m}^{3}$, respectively) were omitted.

In the upper part of fig 3 the nasal mucus flow rate measurements from the middle third of the nose are shown. There was a tendency towards a decreased mucus flow rate in subjects exposed to $\mathrm{SO}_{2}$ only $(0.05<\mathrm{p}<0.1)$, whereas there was no effect of exposure to dust only. In the present experiment with combined exposure to both pollutants, the $\mathrm{SO}_{2}$ exposure caused a significant decrease in the mucus flow rate $(p<0.01)$, more pronounced at the high than at the low concentration. This result indicates that the depression of nasal mucus flow caused by $\mathrm{SO}_{2}$ might be increased by an addition of plastic dust to the $\mathrm{SO}_{2}$ air mixture. It is apparent from fig 3 that this decrease in mucus flow is a pure additive effect without any sign of potentiation. With respect to nasal mucus flow it can be stated that the depressing effect of the studied pollutants was greater in the nose anteriorly than posteriorly, that $\mathrm{SO}_{2}$ had a depressing effect whereas the plastic dust with or without a vanadium coating had no effect, and that no potentiation occurred during combined exposures to both pollutants.

The middle part of fig 3 shows the cross-sectional flow area variations. The analysis of variance showed that during exposure to $\mathrm{SO}_{2}$ alone the subjects had a smaller cross-sectional area than in clean air $(p<0.05)$. There was no effect due either to the $\mathrm{SO}_{2}$ concentration or to the length of the exposure period. In contrast, during exposure to dust only the subjects showed an increase in the cross-sectional nasal area $(p<0.01)$, and even under these circumstances the length or concentration of the exposure did not influence the effect.
In the combined exposure study subjects exposed to the low $\mathrm{SO}_{2}$ concentration had a decrease, and subjects exposed to the high $\mathrm{SO}_{2}$ concentration had an increase in cross-sectional area. This result differs from that of the exposure to $\mathrm{SO}_{2}$ alone and indicates that dust is able to neutralize the constricting effect of high $\mathrm{SO}_{2}$ concentrations.

The lower part of fig 3 shows the $\mathrm{FEV}_{1.0}$. The analysis of variance showed that the air flow was reduced during $\mathrm{SO}_{2}$ exposure $(\mathrm{p}<0.05)$ and during exposure to the low dust concentration $(p<0.01)$, whereas no significant difference appeared between the control condition and the high dust concentration. These results from the dust only experiment are mainly due to two subjects (no 1 \& 3), who had an unusually high flow rate during the control condition on the first day. If these measurements are excluded, there are no significant differences due to dust exposure. During the combined exposure experiment no significant changes were found under any condition. As the clear flow-decreasing effect of $\mathrm{SO}_{2}$ was not found in the combination experiment, it may be concluded that the concomitant dust inhalation changes the response to the inhalation of $\mathrm{SO}_{2}$.

No statistically significant differences were observed in the discomfort voting (fig 4) of the subjects exposed only to $\mathrm{SO}_{2}$ or dust at the low concentration. During the exposure to dust in a concentration of $10 \mathrm{mg} / \mathrm{m}^{3}$, the discomfort was significantly higher $(p<0.05)$ than under the control conditions. In contrast, a significant increase in discomfort voting $(p<0.05)$ was registered for all combinations of $\mathrm{SO}_{2}$ and dust. From these results we conclude that combined exposure to dust and $\mathrm{SO}_{2}$ produces an additive effect with respect to experienced discomfort.

From the very few studies in the literature and from our own investigations, it is also apparent that the presence of an inert dust adds to but does not potentiate the effects of $\mathrm{SO}_{2}$ on the upper airways during exposures of 5 -h duration. The dust particles used were of a size which would not penetrate into the deep lung area optimally. The effects of the dust itself and of dust coated with vanadium were indistinguishable. 
The subjective discomfort occurring with both dust and $\mathrm{SO}_{2}$ exposure bears a strong resemblance to the complaints generally attributed to dry ambient air. In our studies of exposure to dry clean air there was a remarkable absence of subjective discomfort $(5,6)$. The feeling of dryness experienced by the subjects in this study, therefore, was probably due to a stimulation of the trigeminal nerve endings in the nose elicited by the air pollutants.

\section{Acknowledgment}

M Væth, MSc, Institute of Mathematics, University of Århus, Denmark, performed the statistical analyses.

This study was supported in part by USPHHS grants ES 00454 and HL 10342, by OTAN 450 and by Statens lægevidenskabelige Forskningsråd.

\section{References}

1. Amdur MO, Underhill D. The effect of various aerosols on the response of guinea pigs to sulfur dioxide. Arch environ health 16 (1968) $460-468$.

2. American Conference of Governmental Industrial Hygienists. TLV's. Cincinnati, $\mathrm{OH}$ 1977, p 27.

3. Andersen I, Lundqvist GR. Design and performance of an environmental chamber at the University of Aarhus, Denmark. Int j biometeorol 14 (1970) 402-405.
4. Andersen I, Lundqvist GR, Jensen PL, Proctor DF. Human response to controlled levels of sulfur dioxide. Arch environ health 28 (1974) $31-39$.

5. Andersen I, Lundqvist GR, Jensen PL, Proctor DF. Human response to 78-hour exposure to dry air. Arch environ health 29 (1974) 319-324.

6. Andersen I, Lundqvist GR, Proctor DF. Human perception of humidity under four controlled conditions. Arch environ health 26 (1973) 22-27.

7. Andersen I, Lundqvist GR, Proctor DF, Swift DL. Human response to controlled levels of inert dust. Am rev respir dis 119 (1979) 619-628.

8. Burton GG, Corn M, Gee JBL, Vasallo C, Thomas AP. Response of healthy men to inhaled low concentration of gas-aerosol mixtures. Arch environ health 18 (1969) $681-692$.

9. Corn M, Cheng RT. Interactions of sulfur dioxide with insoluble suspended particulate matter. $J$ air pollut control assoc 22 (1972) 870-875.

10. Frank NR, Amdur MO, Whittenberger JL. A comparison of the acute effects of $\mathrm{SO}_{2}$ administered alone or in combination with $\mathrm{NaCl}$ particles on the respiratory mechanisms of healthy adults. Int $j$ air water pollut 8 (1964) 125-133.

11. Hollander M, Wolfe DA. Nonparametric statistical methods. J Wiley \& Sons, New York, NY 1973.

12. Snell RR, Luchsinger PC. Effects of sulfur dioxide on expiratory flow rates and total respiratory resistance in normal human subjects. Arch environ health 18 (1969) 693-698.

13. Sokal RR, Rohlf FJ. Biometry. Freeman \& Co, San Francisco, CA 1969.

14. Ulmer WT. Inhalative Noxen: Schwefeldioxyd. Pneumologie 150 (1974) 83-96.

Received for publication: 10 October 1979 